19 Revue d'histoire du XIXe siècle

Société d'histoire de la révolution de 1848 et des

révolutions du XIXe siècle

$54 \mid 2017$

La part animale du XIX ${ }^{e}$ siècle

\title{
Alain MESSAOUDI, Les arabisants et la France
} coloniale, 1870-1930

Lyon, ENS éditions, 2015, 554 p., $34 €$

Augustin Jomier

\section{OpenEdition}

Journals

Édition électronique

URL : http://journals.openedition.org/rh19/5245

DOI : $10.4000 /$ rh 19.5245

ISSN : 1777-5329

Éditeur

La Société de 1848

Édition imprimée

Date de publication : 1 août 2017

Pagination : 230-232

ISSN : 1265-1354

Référence électronique

Augustin Jomier, «Alain MESSAOUDI, Les arabisants et la France coloniale, 1870-1930 », Revue d'histoire du XIXe siècle [En ligne], 54 | 2017, mis en ligne le 01 juillet 2017, consulté le 25 septembre 2020. URL : http://journals.openedition.org/rh19/5245; DOI : https://doi.org/10.4000/rh19.5245

Ce document a été généré automatiquement le 25 septembre 2020

Tous droits réservés 


\section{Alain MESSAOUDI, Les arabisants et la France coloniale, 1870-1930}

Lyon, ENS éditions, 2015, 554 p., $34 €$

Augustin Jomier

\section{RÉFÉRENCE}

Alain MESSAOUDI, Les arabisants et la France coloniale, 1870-1930, Lyon, ENS éditions, 2015, $554 \mathrm{p} ., 34 €$.

1 L'ouvrage d'Alain Messaoudi s'insère dans les débats suscités par la publication en 1978 d'Orientalism d'Edward Said. L'auteur effectue un retour critique sur la production orientaliste arabisante française, qu'il étudie en détail, de la fin du XVIII siècle à l'Entre-deux-guerres. À partir du cas des arabisants, il restitue les modalités de construction de cette science des langues, des textes et des cultures, offrant à la fois à une histoire sociale de l'orientalisme savant et une histoire culturelle de la colonisation française au Maghreb. L'auteur reconstitue tout un milieu de savants, d'interprètes et de professeurs, dans lequel se trouvent aussi des Maghrébins et des Proche-orientaux. Cette entreprise colossale est doublée d'un impressionnant volume d'annexes (disponible en ligne). Impressionnante aussi, l'ampleur des espaces embrassés - la France, sa colonie et ses protectorats du Maghreb, sans oublier ses institutions savantes au Proche-Orient.

2 L'ouvrage est composé de trois parties. La première porte sur les études arabes en France de 1780 à 1840. Paris constitue un environnement favorable durant le XVIII ${ }^{e}$ siècle, notamment grâce à l'École des Jeunes de langue, fondés en 1669. Dynamiques, les études arabes sont désorganisées par la Révolution, mais cet héritage savant est recueilli par la fondation de l'École Spéciale des Langues Orientales, en 1795. La campagne d'Égypte et les réfugiés qu'elle génère favorisent la centralité de la langue arabe dans l'orientalisme français. Sous la Monarchie de juillet, les arabisants français travaillent dans un climat général de forte valorisation de la culture arabe : les Arabes 
sont perçus comme un peuple libre, puisque proche de l'état de nature, et victime du despotisme ottoman.

3 La deuxième partie de l'ouvrage ("Les études arabes à l'épreuve de l'occupation algérienne - 1830-1870») montre que l'expédition d'Alger, de ce point de vue, ne constitue pas un tournant. Les savants recrutés pour l'expédition forment un ensemble hétéroclite - anciens élèves des Langues orientales, chrétiens orientaux recrutés lors de l'expédition d'Égypte et Maghrébins. Sur le terrain algérien, sous la Monarchie de Juillet, militaires et colons trouvent un intérêt pratique à cet apprentissage, mais certains sont aussi mus par une sympathie pour les arabophones. Une figure de médiateur, l'interprète, idéalisé à tort dans l'historiographie, est pourtant en voie d'européanisation dès 1845: une réorganisation du corps, visant à le revaloriser, conduit à la marginalisation des Maghrébins.

4 Sous la deuxième République et l'Empire, les dirigeants de la colonie promeuvent de façon concomitante le français et l'arabe, que ce soit par l'enseignement, l'imprimerie ou un journal officiel bilingue. L'arabe n'est toutefois pas massivement introduit dans les établissements publics. C'est une scolarisation «française » des enfants, Européens comme musulmans, qui est avant tout visée. La fondation d'un précaire enseignement à destination des Algériens - écoles arabes-françaises et médersas - favorise la conception de l'arabe comme langue réservée à l'enseignement des indigènes. La fin du Second Empire confirme l'échec des tentatives pour donner à l'arabe un statut de langue nationale moderne en Algérie et l'intégrer à une culture impériale française.

5 L'ouvrage confirme que la mise à distance de l'« Orient » est tardive et incomplète : elle ne se joue pas en 1830, mais autour de 1870. C'est ce qu'étudie la troisième partie du livre, «Les arabisants entre académisme et mission civilisatrice (c. 1870-c. 1930)». L'auteur évalue d'abord la part de l'inflexion coloniale dans l'enseignement qui se développe à Paris, après le choc de Sedan en 1870 et la refonte de l'université française. L'arabe connaît une institutionnalisation croissante et un tournant savant, à l'École des Langues Orientales Vivantes, à l'École Pratique des Hautes Études - toutes deux réorganisées. Le milieu savant orientaliste se professionnalise et se structure, en même temps qu'il échoue à prendre pied dans l'université, surtout en province. Dans l'École coloniale et les instituts coloniaux de province, le modèle de l'ÉLOV se répand: savant et pratique, colonial mais favorable à un respect des traditions culturelles des pays colonisés et protégés.

Sous la Troisième République et jusqu'en 1914, Alger est le lieu des investissements les plus importants dans la recherche et l'enseignement de l'arabe. Un centre universitaire y est créé en 1879. Un effort y est consenti pour enseigner davantage l'arabe dans le secondaire et le supérieur, notamment avec l'institution de l'agrégation d'arabe en 1906. Il s'agit pour l'administration coloniale de donner des cadres arabisants - y compris chez les Européens - à la société. L'ouvrage s'achève sur les carrières de la génération de savants formés au tournant du siècle à Alger et s'impliquant dans les orientations politiques coloniales de la France. Dans ce dernier chapitre, les notices biographiques tendent malheureusement à prendre le pas sur la démonstration d'ensemble. Une exhaustivité moindre aurait peut-être rendu le propos plus percutant, mais l'idée majeure défendue par l'auteur s'impose: le rapport des orientalistes à l'Orient est plus complexe que Said ne l'affirmait. Des locuteurs natifs ont pris une part active à leur entreprise savante. Des espaces de contacts entre eux et les savants 
européens se sont maintenus durablement. Le Proche-Orient - tierce pôle d'une histoire principalement franco-maghrébine - joue à cet égard un rôle central.

7 L'ouvrage constitue aussi une contribution importante au débat sur la culture coloniale en France, dont il montre bien la complexité. Du point de vue de l'histoire culturelle, 1830 ne marque pas une césure. Le goût pour des modèles culturels arabes précède largement l'épisode colonial français au Maghreb et l'altérisation des Arabes, la tendance à dénigrer leur langue sont, au contraire, plus tardives, se développant véritablement après 1870 . Il y a donc une diffusion précoce d'une culture orientaliste, mais sa marque colonialiste est plus tardive. $\mathrm{Si}$, à la fin du XIX ${ }^{\mathrm{e}}$ siècle, les savants ont indéniablement mis à distance les locuteurs arabophones, les approches savantes qu'ils ont privilégiées, liées au développement de sciences comme l'anthropologie ou la sociologie, contredisent l'image d'érudits philologues. Politiquement se dessine autour d'eux dès la Monarchie de Juillet et de façon récurrente jusqu'à l'établissement du protectorat marocain, un milieu qui considère que le projet colonial français ne peut réussir qu'en associant les populations locales.

Un grand souci du détail rend parfois le propos touffu, mais le livre d'Alain Messaoudi n'en constitue pas moins un apport majeur à l'histoire culturelle de la France en ses espaces coloniaux et un jalon essentiel à l'historiographie de l'orientalisme savant européen. Fondé sur une quantité de sources variées, de langue française, Les arabisants et la France coloniale ouvre de nombreuses pistes pour une histoire culturelle du Maghreb contemporain. À l'avenir, une lecture croisée des sources de langue française et arabe permettra, à n'en pas douter, de poursuivre l'œuvre entamée ici d'étude des échanges et collaborations entre savants français et arabes. Une piste paraît plus particulièrement suggestive, celle d'une histoire de la langue arabe, de ses usages et de ses représentations, tant la construction de la diglossie et celle du mépris pour les parlers dialectaux semblent concomitante parmi les élites arabes et européennes. 